\title{
Longitudinal investigations of anatomical and morphological development of the gastrointestinal tract in goats from colostrum to postweaning
}

\author{
M. M. Abdelsattar, ${ }^{1,2} \odot$ Y. Zhuang, ${ }^{1}$ K. Cui, ${ }^{1}{ }^{\text {Y. Bi }}{ }^{1}{ }^{1}$ M. Haridy, ${ }^{3}$ and N. Zhang ${ }^{1 *}$ (1) \\ ${ }^{1}$ Institute of Feed Research of Chinese Academy of Agricultural Sciences, Key Laboratory of Feed Biotechnology \\ of the Ministry of Agriculture and Rural Affairs, Beijing, 100081, China \\ ${ }^{2}$ Animal and Poultry Production Department, Faculty of Agriculture, South Valley University, Qena, 83523, Egypt \\ ${ }^{3}$ Department of Pathology and Clinical Pathology, Faculty of Veterinary Medicine, South Valley University, Qena 83523, Egypt
}

\begin{abstract}
The digestive tract development in goat kids around weaning is vital to the establishment of digestion and absorption function, growth, and health of adults. The objective was to explore the effects of age and solid feed on the anatomical and morphological development of the gastrointestinal tract of Laiwu Black goat kids. Forty-eight female Laiwu Black goats at 8 ages (1, 7, $14,28,42,56,70$, and $84 \mathrm{~d}$; 6 goats per group) were selected and killed for anatomical and morphological analysis. The goats experienced the following 4 diet phases: maternal colostrum ( $\mathrm{MC} ; \mathrm{d} 1, \mathrm{~d} 7)$, maternal milk (MM; d 14, d 28), maternal milk plus solid diet (MMSD; d 42, d 56) and only solid diet (OSD; d 70, d 84 ). The body and carcass weights were not significantly changed during $\mathrm{MC}$ and MM phases but changed during the MMSD phase. The absolute growth of body and carcass weights were higher in the MMSD phase than in MM phase. In addition, the dressing percentage was the highest in the MMSD phase. The body size indices evolved progressively and increased over time. The percentage of internal and external organs to body weight decreased over time, whereas the percentage to complex stomach percentage increased. The rumen and omasum weight experienced synchronous absolute growth over time, especially in the OSD phase. In contrast, the absolute growth of the reticulum and abomasum was the highest in MMSD and MC phases, respectively. After weaning, the goats showed the highest papillae height, lamina propria, muscle layer thickness, and epithelial thickness. The OSD phase showed the highest colonic mucosa thickness, ileal villus height, and ileal muscle layer thickness. The crypt depth was higher in the MMSD phase than in the MM phase. Moreover, the crypt depth and muscle layer thickness of jejunum increased over time. Furthermore, duode-
\end{abstract}

Received July 25, 2021.

Accepted November 29, 2021.

*Corresponding author: zhangnaifeng@caas.cn nal crypt depth, muscle layer thickness, and epithelial thickness increased in the OSD phase compared with other stages. In conclusion, the histological investigation supports the improvement of the morphological development of the digestive tract and the growth performance in the solid feed phase. It is recommended to add solid food as early as 4 wk old.

Key words: anatomic development, gut morphology, gastrointestinal tract, solid feed, weaning

\section{INTRODUCTION}

Goats (Capra hircus) are a global livestock species because they provide essential products, such as milk, meat, and skin (Wang et al., 2021). The number of goats in China at the end of 2020 was 133.45 million (National Bureau of Statistics of China, 2020). The rapid economic growth increased the demand for improving the quality and productivity of goats. After birth, the digestive tract exhibits morphological, biochemical, and ultrastructural changes that contribute to its maturation (Lopez-Pedrosa et al., 1998). The digestive tract development in goat kids has a long-term effect on the establishment of digestion and absorption function, production performance, and health status (Jiao et al., 2016; Diao et al., 2019). Therefore, it is vital to master the rules of anatomical and morphological development of the gastrointestinal tract to tap the growth potential of goats and promote industrial development (Jin et al., 2018). The knowledge about the longitudinal effects of gastrointestinal physiology, especially in the transition weaning stage, could be helpful to increase our understanding of the anatomical and morphological development of the digestive tract to control stress after weaning, to avoid challenges in livestock production.

The small intestine is the main site for digestion of liquid feed, such as maternal colostrum (MC), maternal milk (MM), or milk replacer (MR; Górka et al., 2011). The results of Blättler et al. (2001) showed the improvement of small intestine development in neonatal 
calves fed colostrum. The digestion of goat kids shifts from the intestine to the rumen during the transition of diets from milk to solid feed ( $\mathrm{Li}$ et al., 2019a). Adequate nutrition, meanwhile, guarantees gastrointestinal development, immunity, and metabolite changes (Liu et al., 2017; Saro et al., 2018; Yang et al., 2018). Several studies show that the solid diet in early life substantially affects the early development of the rumen epithelium (Lv et al., 2019) and reduces nutritional deficiency and weight loss after weaning (Khan et al., 2011). Furthermore, rumen development and VFA production stimulated by solid feed intake promotes the nutrient availability in the intestine and its morphology development (Baldwin, 1999). Therefore, further studies are needed to explore the effects of nutrition on the digestive tract development of young goats. Age is also an essential factor to be considered because it can change the physiology and function of the gut (Merchant et al., 2016). In goats, the effects of age from birth to $\mathrm{d} 70$ and feeding system (supplemental feeding vs. grazing) have been reported in rumen development (Jiao et al., 2015b) and the small intestine (Li et al., 2016). They show an improvement of gastrointestinal morphology over time, irrespective of the feeding system (Jiao et al., 2015b; Li et al., 2016). However, this development was strong during the weaning and the diet-change periods (Jiao et al., 2015b; Li et al., 2016), suggesting that the age effects are still confounded by the dietary changes. The study of Jiao et al. (2016) showed that the gut bacteria of grazing goat kids undergo stage-associated changes from the preruminant to ruminant stages.

The Laiwu Black goat is an excellent local breed in China. In the early Qing Dynasty, a distribution center for goat breeding and trading was formed in the Laiwu area. With continuous selection, the Laiwu Black goat formed the characteristics of high fecundity, resistance to rough feeding, strong disease resistance, and delicious meat (Liu et al., 2012). By the late Qing Dynasty, the food culture of eating meat and drinking soup made by Laiwu Black goat had spread and became the most famous food in the hotel at that time. Finally, the Laiwu Black goat was recognized as an excellent local breed by China in 1999, and was listed as a protected breed of livestock genetic resource by the state in 2013 (Liu et al., 2012). However, to the best of our knowledge, there has been no data published about the anatomic and morphological development of the digestive tract of the Laiwu Black goat during transition weaning and the influence of solid feed on this process. Further studies are needed to clarify the development rules of the digestive tract with changes in diet and age. It is hypothesized that the staged development of rumen morphology of the Laiwu Black goat is associated with the longitudinal change of diets from liquid to solid, and to the phased development of the small and large intestines as well as the liver, kidney, and other organs. Therefore, the purpose of this study was to explore the anatomical and morphological development of the gastrointestinal tract and the growth performance of Laiwu Black goat kids by studying the colostrum, milk, milk and starter, and starter stages at 8 time points from birth to $84 \mathrm{~d}$ of age.

\section{MATERIALS AND METHODS}

\section{Animals, Diets, and Housing}

The experiment was approved by the Animal Ethics Committee of the Chinese Academy of Agricultural Sciences (with protocol AEC-CAAS-20191105; approval date: November 3, 2019). The experiment was conducted at Xiang Feng black goat farm, Laiwu district, Jinan city, Shandong, China (latitude, $36^{\circ} 02^{\prime} \mathrm{N}$; longitude $117^{\circ} 19^{\prime} \mathrm{E}$ ).

A total of 48 healthy female goats of different ages $(1,7,14,28,42,56,70$, and 84 d old) were randomly selected from the goat farm. One goat at d 1 with abnormal conditions was excluded from the experiment, so the total number of goats was 47. All the experimental goats were pure Laiwu Black goats with the same genetic background and raised at the same environment. The young goats' feeding regimens were as follows (Figure 1): MC was fed after birth, and MM was followed from d 8. After d 28, the solid diet was introduced with the MM (MMSD). Then, the goats were weaned at $60 \mathrm{~d}$ of age and offered only solid diet (OSD). This feeding management system was designed to elicit the stress of weaning.

The goats were under daily farm veterinary care throughout the experiment. After birth, goats were housed in well-ventilated pens with dams $(14 \mathrm{~m} \times 6 \mathrm{~m}$ : 20 animals per pen). At d 60, the goats were separated from their dams and transferred into individual pens with a slatted floor $(4 \mathrm{~m} \times 4 \mathrm{~m}$ : 10 goats per pen $)$ until the end of the trial (d 84). During the experimental period, goats had free access to water and were offered a commercial starter diet ad libitum (Kangmeihua feed Company, China; Supplemental Table S1, https://doi .org/10.6084/m9.figshare.17111312.v1), which was formulated according to NRC (2007). The chemical analysis of solid diet samples was performed at the end of the experiment in the Laboratory of Ruminant Physiology and Nutrition, Feed Research Institute of Chinese Academy of Agricultural Sciences (Supplemental Table S1). Samples were analyzed for DM (AOAC International, 2003; method 934.01), CP (AOAC International, 2003; method 954.01), ash (AOAC International, 2003; method 942.05), ether extract (AOAC International, 
2003; method 920.39), calcium (AOAC International, 2006; method 968.08), phosphorus (AOAC International, 2006; method 985.01), and NDF and ADF using the method described by Van Soest et al. (1991). Total energy and NFC were calculated according to NRC (2001) using the following equations:

$\mathrm{NFC}, \%=100-(\mathrm{NDF}+\mathrm{CP}+$ ether extract + ash $) ;$

$$
\begin{gathered}
\text { Total energy, Mcal } / \mathrm{kg}= \\
(\mathrm{NFC} / 100) \times 4.2+(\mathrm{NDF} / 100) \times 4.2+(\mathrm{CP} / 100) \\
\times 5.6+(\text { ether extract } / 100) \times 9.4
\end{gathered}
$$

\section{Growth Performance and Carcass Measurements}

All the goat kids were taken to an on-farm experimental abattoir for slaughter. The live BW was recorded, and the body size indices (oblique body length, height, cannon bone circumference, chest circumference, and chest depth) were measured using tape with an accuracy of $0.1 \mathrm{~cm}$ immediately before the slaughter of goats. Then, the goats were anesthetized using sodium pentobarbitone, killed by exsanguination from the jugular vein, skinned, and eviscerated according to the method described by Chai et al. (2018). The internal organs (heart, liver, spleen, lungs, and kidneys) and external organs (head, hoof, and skin) were weighed. The hot carcass weight $(\mathbf{H C W})$ and the dressing percentage were determined. The empty weight of rumen, reticulum, omasum, and abomasum were recorded. The rumen volume was recorded by filling the rumen with water. Furthermore, the forestomach parts were expressed as a percentage of live BW or complex stomach weight. The absolute growth of BW, $\mathrm{HCW}$, internal and external organs, stomach chambers, and rumen volume were calculated according to the following equation:

$$
\text { Absolute growth rate }=\left(\mathrm{W}_{2}-\mathrm{W}_{1}\right) /\left(\mathrm{T}_{2}-\mathrm{T}_{1}\right),
$$

where $\mathrm{W}_{1}$ is the initial value at time $\mathrm{T}_{1}$, and $\mathrm{W}_{2}$ is the final value at time $T_{2}$. The absolute growth rate was used to distinguish the growth intensity of different feeding stages.

\section{Histomorphological Examination}

Rumen, small intestine (duodenum, jejunum, and ileum), and large intestine (colon) tissue samples were collected. Tissue samples (about $1 \mathrm{~cm}^{2}$ ) were separated with a sharp scalpel from the nonsqueezed parts of the organ, washed with prechilled phosphate buffer solution $(\mathrm{pH}=7.1)$, placed in an embedding box, and immersed in a $10 \%$ formalin solution immediately. After fixation, samples were dehydrated by a TSJ-II fully automatic closed tissue dehydrator (Zhongwei Electronic Instrument Co., Ltd.). The samples were trimmed and embedded in paraffin blocks using a BMJ-III type embedding machine (Zhongwei Electronic Instrument Factory). The formed blocks were cut on a rotary microtome (Leica-2016) and stained with hematoxylin and eosin (Chengdu Lilai Biological Technology Co., Ltd.). The histomorphological examination was done using a BA400 digital trinocular micro-camera (McAudio Industrial Group Co., Ltd.) and Image-Pro-Plus 6.0 software (American Media Cybernetics). Six pictures were taken for each sample, including 2 objective lenses of $4 \times$ and $40 \times$. Ten sets of data were measured for each slice number. The small intestine indicators included villus height, crypt depth, and muscle layer thickness by lens $4 \times$, as well as the epithelial thickness by lens $40 \times$. Colonic mucosal thickness and muscle layer thickness were measured by lens $4 \times$, and the colonic epithelial thickness was measured by lens $40 \times$. The rumen indicators included rumen papillae height, rumen papillae width, lamina propria thickness, muscle layer thickness $(4 \times$ lens), epithelial thickness, and stratum corneum thickness $(40 \times$ lens $)$.

\section{Statistical Analysis}

The data were tested for normality before the statistical analysis. The data analysis was performed by one-way ANOVA using IBM SPSS Statistics 22 (IBM Corp.). The statistical model was as follows:

\section{Birth}

Preweaning stage

Postweaning stage

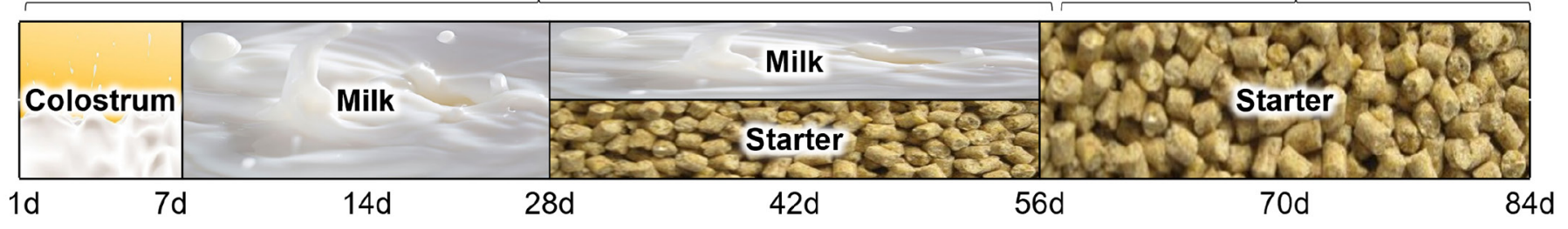

Figure 1. The experimental feeding management system from birth to $84 \mathrm{~d}$ of age in goats $(\mathrm{n}=47)$. 


$$
\mathrm{Y}_{\mathrm{i}}=\mu+\mathrm{T}_{\mathrm{i}}+\varepsilon_{\mathrm{i}},
$$

where $Y_{i}$ is the dependent variable, $\mu$ is the overall mean, $T_{i}$ is the fixed effect of group (8 time points), and $\varepsilon_{\mathrm{i}}$ is the error term. Orthogonal polynomials were used to test polynomial trends (linear, quadratic, and cubic effects). Statistical differences between the means of groups were tested using Duncan's multiple range test. In addition, the differences were considered significant at the level of $P<0.05$.

\section{RESULTS}

\section{Growth Performance}

The BW and HCW increased linearly $(P<0.01)$ over time, reaching $10.3 \pm 0.41$ and $4.97 \pm 0.21 \mathrm{~kg}$ at d 84 , respectively $( \pm \mathrm{SE}$; Table 1$)$. The goats were heavier $(P$ $<0.01$ ) at d 84 than d 42, at d 42 than d 28, and at d 28 than $\mathrm{d} 1$. The dressing percentage showed a quadratic increase $(P<0.01)$ over time and reached $52.7 \pm 0.55 \%$ in the MMSD phase. The absolute growth of BW was higher $(P<0.05)$ in the MMSD phase $(114 \pm 10.1 \mathrm{~kg})$ than in the MM phase $(65.1 \pm 7.31 \mathrm{~kg}$; Figure 2$)$. In addition, the absolute growth of HCW was higher $(P<$ $0.05)$ in the MMSD phase than in both OSD and MM phases $(63.6 \pm 9.4,25.6 \pm 10.4$, and $37.5 \pm 3.25 \mathrm{~kg}$, respectively). Moreover, the oblique body length and body height experienced a synchronous linear increase $(P<0.01)$ over time and reached 49.5 and $44.5 \mathrm{~cm}$ at d 84, respectively (Table 1 ). The goats showed higher values at d 42 than d 14 and d 84 than d 42 . Moreover, the chest circumference was higher $(P<0.01)$ at $\mathrm{d} 14$ than $\mathrm{d} 7, \mathrm{~d} 42$ than $\mathrm{d} 28$, and $\mathrm{d} 70$ than $\mathrm{d} 42$. In addition, the cannon bone circumference and chest depth showed a slow increase $(P<0.01)$ over time; the $\mathrm{d} 42$ values were higher than $d 1$ values $(7.17$ vs. $6.10 \mathrm{~cm}$ for cannon bone circumference; 18.0 vs. $8.80 \mathrm{~cm}$ for chest depth).

\section{Organ Development}

The internal and external organs increased $(P<$ 0.01 ) over time, as shown in Table 2 . The heart was heavier at $\mathrm{d} 42$ than $\mathrm{d} 1$ (40.1 vs. $25.2 \mathrm{~g}$ ) and $\mathrm{d} 56$ than d 28 (47.8 vs. $32.4 \mathrm{~g}$ ). In addition, the liver was heavier at d 42 than d 1 (142 vs. $92.6 \mathrm{~g}$ ) and d 70 than d 42 (197 vs. $142 \mathrm{~g}$ ). In addition, the spleen was heavier at d 42 than $\mathrm{d} 7$ (15.2 vs. $7.40 \mathrm{~g}$ ) and d 56 than $\mathrm{d} 28$ (20.4 vs. $13.9 \mathrm{~g})$. The lungs were heavier at $\mathrm{d} 42$ than $\mathrm{d} 7$ ( 85.2 vs. $53.6 \mathrm{~g}$ ) and $\mathrm{d} 70$ than $\mathrm{d} 42$ (117 vs. $85.2 \mathrm{~g}$ ). The kidney weight was higher at d 70 and $\mathrm{d} 56$ than $\mathrm{d}$ 1 (38.3, 38.7, and $25.1 \mathrm{~g}$, respectively). Moreover, head and hoof were heavier at d 28 than d 1 (339 vs. $253 \mathrm{~g}$

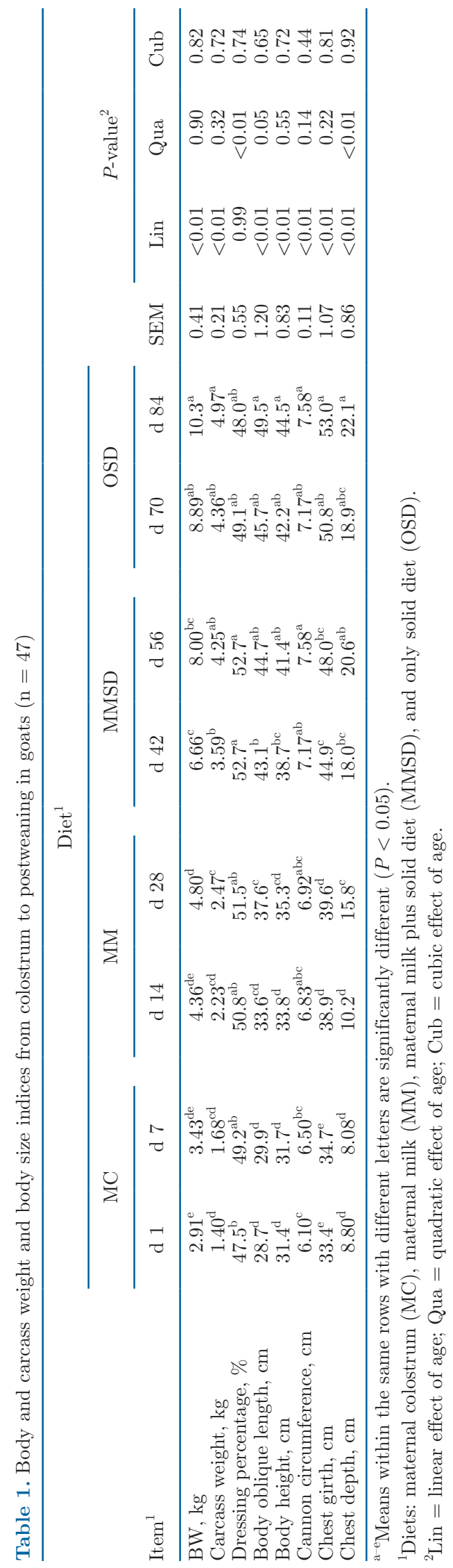




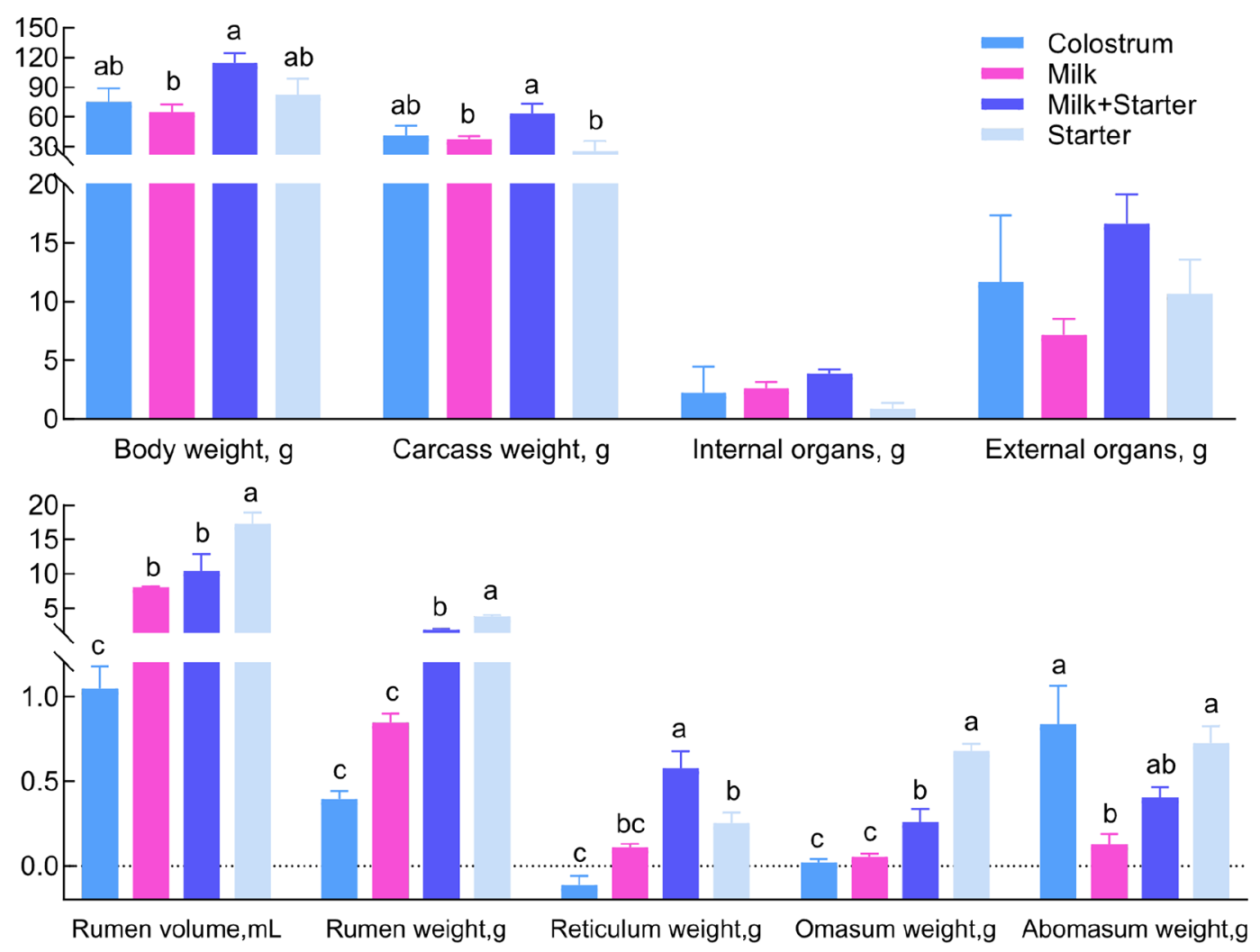

Figure 2. The absolute growth of BW, carcass weight, internal and external organs, complex stomach chamber weight, and rumen volume in goats $(\mathrm{n}=47)$ fed different diets from colostrum to $84 \mathrm{~d}$ of age. Different letters $(\mathrm{a}-\mathrm{c})$ represent a significant difference between the different feeding stages $(P<0.01)$. Error bars represent SEM.

for the head; 135 vs. $90.8 \mathrm{~g}$ for hoof). In addition, the skin was heavier at d 84 than $\mathrm{d} 42$ and $\mathrm{d} 42$ than $\mathrm{d} 7$ $(1,033,809$, and $533 \mathrm{~g}$, respectively).

In contrast, the organ indices expressed as a percentage of BW decreased over time $(P<0.05$; Table 2$)$. Heart index was lower at d 70 than $\mathrm{d} 28$, and $\mathrm{d} 28$ than d 14 (0.54, 0.67, and 0.79\%, respectively). In addition, the liver and hoof indices were lower at d 42 than d 28 ( 2.14 vs. $2.79 \%$ for the liver; 2.08 vs. $2.84 \%$ for hoof). The spleen index was lower at d 84 than $d 28(0.18$ vs. $0.30 \%)$. Moreover, the lungs index was lower at $\mathrm{d}$ 42 than $\mathrm{d} 1$ (1.29 vs. 1.65\%). Furthermore, the kidney and head indices were lower at d 56 than $\mathrm{d} 14$ and d 14 than $\mathrm{d} 1(0.49,0.67$, and $0.88 \%$, respectively, for kidney; $6.24,7.35$, and $8.81 \%$, respectively, for head). In addition, the skin index was lower at d 28 than $\mathrm{d} 14$ (12.3 vs. $15.3 \%)$ and d 84 than d 28 (10.0 vs. $12.3 \%$ ). The absolute growth of the organ was not significantly affected over the different feeding stages (Figure 2).

\section{Anatomic Development of Digestive Tract}

The rumen volume increased quadratically $(P<$ $0.05)$ over time, as shown in Table 3; it was higher at d 70 than d 56 ( 750 vs. $483 \mathrm{~mL})$, d 56 than d 28 (483 vs. $190 \mathrm{~mL})$, and $\mathrm{d} 42$ than d 14 (376 vs. $54.2 \mathrm{~mL})$. In addition, the rumen was heavier $(P<0.01)$ at $\mathrm{d} 80$ than d 70 (189 vs. $138 \mathrm{~g})$, d 70 than d 56 (138 vs. 82.5 $\mathrm{g}$ ), and d 42 than d 28 (67.4 vs. $30.4 \mathrm{~g})$. Moreover, the reticulum was heavier $(P<0.01)$ at $\mathrm{d} 70$ than $\mathrm{d} 42$ and d 42 than d 28 (28.5, 16.3, and 7.04 g, respectively). Furthermore, the omasum was heavier $(P<0.01)$ at d 84 than d 70, d 70 than d 56, and d 56 than d 28 (30.1, 24.0, and $3.82 \mathrm{~g}$, respectively). In addition, the abomasum weight showed a quadratic increase $(P<$ 0.01 ) over time; it was heavier at d 56 than d 14 (46.6 vs. $32.8 \mathrm{~g}$ ) and $\mathrm{d} 70$ than $\mathrm{d} 28$ (49.1 vs. $34.1 \mathrm{~g}$ ). In addition, the highest abomasum weight was $66.9 \mathrm{~g}$ at $\mathrm{d}$ 84. Moreover, complex stomach weight was heavier $(P$ $<0.01)$ at $\mathrm{d} 42$ than $\mathrm{d} 28$ (126 vs. $75.4 \mathrm{~g})$ and $\mathrm{d} 84$ than d 70 (316 vs. 239 g).

The forestomach chambers indices as a percentage of the complex stomach are shown in Table 3. The rumen index increased quadratically $(P<0.01)$ over time (Table 3); it was higher at d $28(40.9 \%)$ than $d$ $14(28.8 \%)$ and lower than d $42(53.1 \%)$. Moreover, the reticulum index at $\mathrm{d} 42$ was higher than $\mathrm{d} 7(P<$ $0.01 ; 12.8$ vs. $8.58 \%)$. In addition, the omasum index 


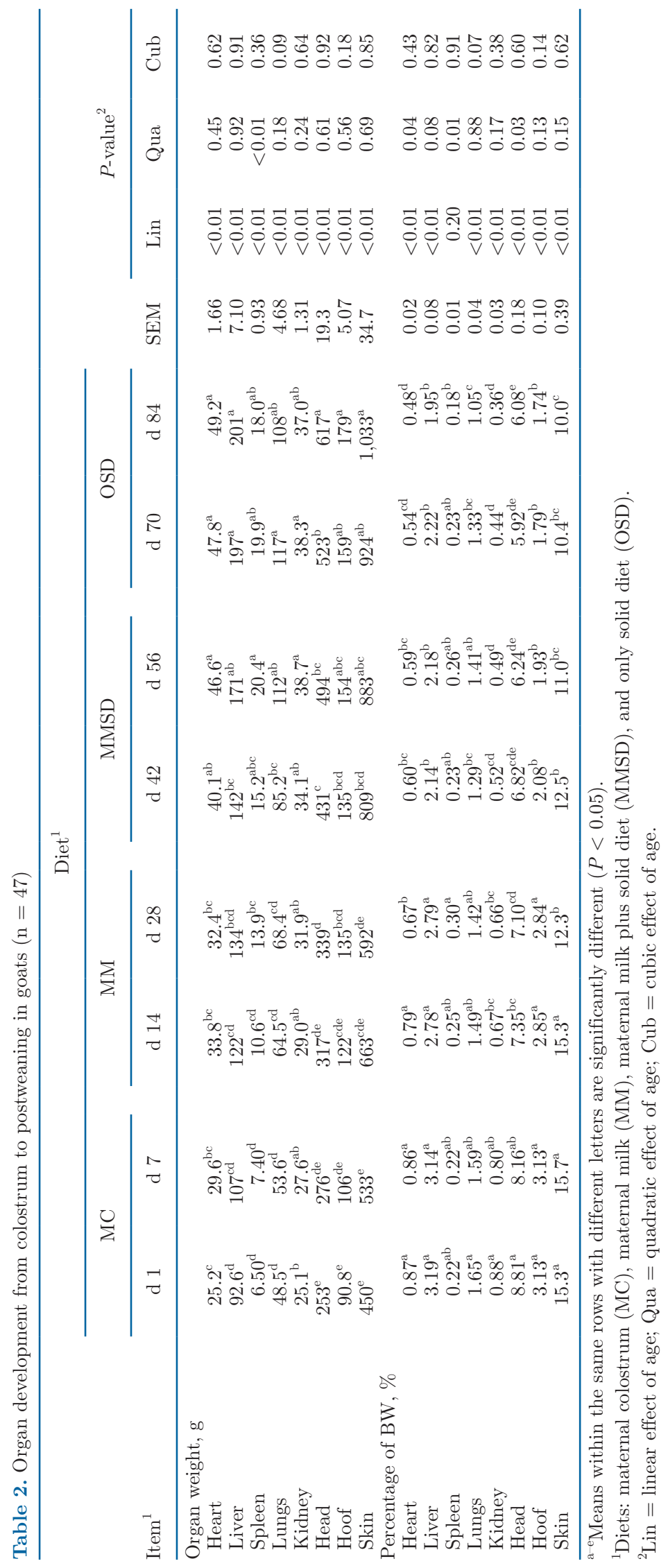




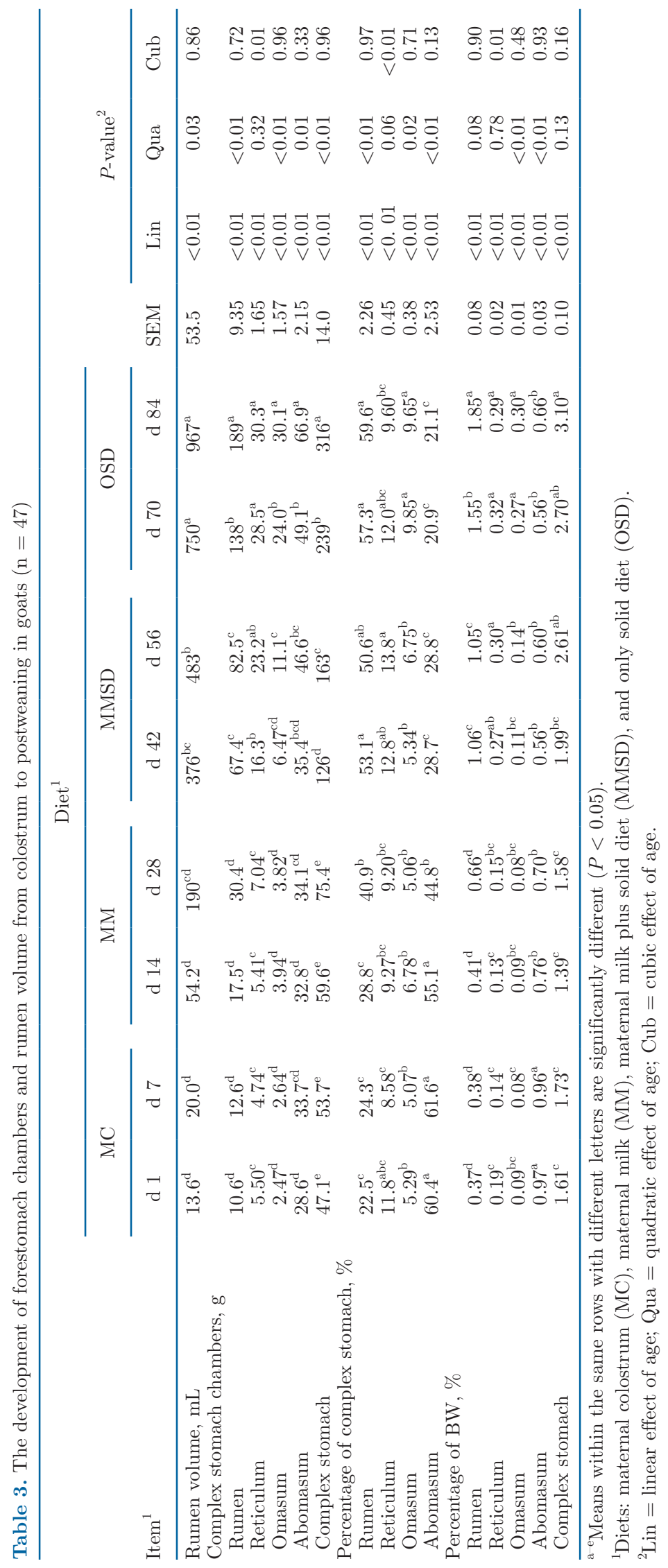


was higher at $\mathrm{d} 70$ than $\mathrm{d} 56(P<0.05 ; 9.85$ vs. 6.75$)$. However, the abomasum index showed a significant quadratic decrease $(P<0.01)$ over time; it was higher at d 28 than older goats.

Moreover, the complex stomach parts indices expressed a percentage of $\mathrm{BW}$ in Table 3 showed that the rumen index was higher $(P<0.01)$ at $\mathrm{d} 84$ than $\mathrm{d} 70$, d 70 than $\mathrm{d} 42$, and $\mathrm{d} 42$ than $\mathrm{d} 28(1.85,1.55,1.06$, and 0.66 , respectively; Table 3$)$. In addition, the reticulum index was higher at $\mathrm{d} 42$ than $\mathrm{d} 14(P<0.01 ; 0.27$ vs. $0.13 \%)$. Moreover, the omasum index at $\mathrm{d} 70$ was lower than $\mathrm{d} 56(P<0.01 ; 0.27$ vs. $0.14 \%)$. In addition, the complex stomach index was higher $(P<0.01)$ at $\mathrm{d} 56$ than $\mathrm{d} 28$ (2.61 vs. $1.58 \%)$, and $\mathrm{d} 84$ than $\mathrm{d} 42(3.10$ vs. $1.99 \%)$. However, the abomasum percentage of $d 14$ $(0.76 \%)$ and onwards were lower $(P<0.01)$ than $d 7$ $(0.96 \%)$.

As shown in Figure 2, the OSD phase had the highest $(P<0.01)$ absolute growth of rumen volume $(17.3 \pm$ $1.66 \mathrm{~mL}$; linear effect), rumen weight $(3.8 \pm 0.23 \mathrm{~g}$; quadratic effect), and omasum weight $(0.68 \pm 0.04 \mathrm{~g}$; quadratic effect). The goats showed the highest $(P<$ $0.01)$ reticulum absolute growth in the MMSD phase $(0.58 \pm 0.10 \mathrm{~g}$; cubic effect). Absolute growth of the abomasum was quadratically higher $(P<0.01)$ in the $\mathrm{MC}$ and OSD phases than in the MM phase $(0.84 \pm$ $0.23,0.72 \pm 0.10$, and $0.13 \pm 0.06 \mathrm{~g}$, respectively).

\section{Rumen Morphology}

Rumen morphology results (Table 4 and Supplemental Figure S1, https://doi.org/10.6084/m9.figshare .17111312.v1) revealed that the rumen papillae height was higher $(P<0.05)$ at $\mathrm{d} 28$ than $\mathrm{d} 14(769$ vs. 618 $\mu \mathrm{m})$ and $\mathrm{d} 70$ than $\mathrm{d} 56(1,046$ vs. $838 \mu \mathrm{m})$. The rumen papillae width was wider at d 42 than d $28(P<$ $0.01 ; 332$ vs. $272 \mu \mathrm{m})$. The lamina propria thickness was higher $(P<0.01)$ at $\mathrm{d} 56$ than $\mathrm{d} 1$ (182 vs. 127 $\mu \mathrm{m})$ and $\mathrm{d} 84$ than $\mathrm{d} 56(237$ vs. $182 \mu \mathrm{m})$. The ruminal muscle layer thickness was thicker $(P<0.01)$ at $\mathrm{d} 70$ than $\mathrm{d} 28$ (915 vs. $734 \mu \mathrm{m})$ and $\mathrm{d} 84$ than $\mathrm{d} 56(1,031$ vs. $819 \mu \mathrm{m})$. In addition, the ruminal epithelial thickness was thicker at $\mathrm{d} 7$ than $\mathrm{d} 1(P<0.01 ; 62.2$ vs. $49.2 \mu \mathrm{m}$ ), and the thickest value was $90.6 \mu \mathrm{m}$ at $\mathrm{d} 84$. Furthermore, the stratum corneum thickness increased cubically $(P<0.01)$ over time; it was higher at $\mathrm{d} 42$ than d 28 (21.7 vs. $10.2 \mu \mathrm{m})$ and d 56 than d $42(31.3$ vs. $21.7 \mu \mathrm{m})$.

\section{Intestinal Morphology}

The colonic mucosal thickness showed a quadratic increase over time $(P<0.01$; Table 5 and Supplemen-

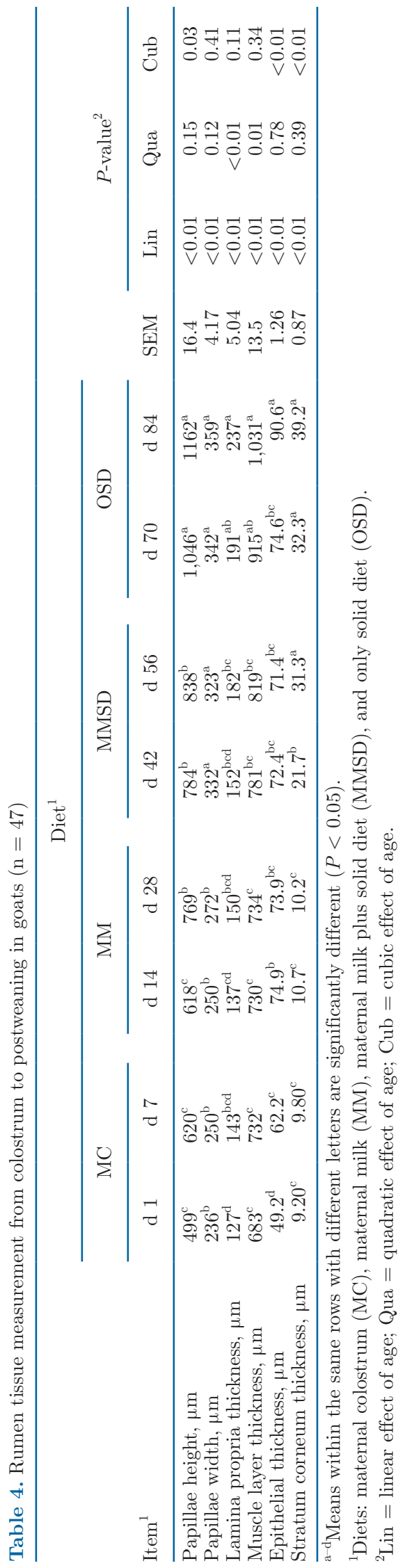


tal Figure S2, https://doi.org/10.6084/m9.figshare $.17111312 . v 1)$; it was higher at d 28 than d 14 (536 vs. $411 \mu \mathrm{m})$ and $\mathrm{d} 70$ than $\mathrm{d} 42(619$ vs. $539 \mu \mathrm{m})$. In addition, the colonic muscle layer thickness increased quadratically $(P<0.01)$ over time; it was higher at $\mathrm{d}$ 7 than $\mathrm{d} 1$ (239 vs. $179 \mu \mathrm{m})$ and $\mathrm{d} 84$ than $\mathrm{d} 14(277$ vs. $240 \mu \mathrm{m})$. However, no significant differences were detected in the colonic epithelial thickness.

The ileal villus height did not show significant differences from birth to $\mathrm{d} 60$, whereas at $\mathrm{d} 70$ it was higher $(P<0.01)$ than $\mathrm{d} 42(601$ vs. $533 \mu \mathrm{m}$; Table 5 and Supplemental Figure S3, https://doi.org/10.6084/ m9.figshare.17111312.v1). In addition, the ileal crypt depth increased linearly $(P<0.01)$ over time; it was higher at d 42 than d 14 (243 vs. $191 \mu \mathrm{m})$ and $\mathrm{d} 84$ than d 28 ( 275 vs. $228 \mu \mathrm{m})$. In addition, ileal epithelial thickness and muscle layer thickness increased cubically $(P<0.01)$ over time. The ileal epithelial thickness was higher $(P<0.01)$ at $\mathrm{d} 7$ than $\mathrm{d} 1(22.3$ vs. $19.5 \mu \mathrm{m})$. The ileal muscle layer thickness was higher at $\mathrm{d} 14$ than d 1 (143 vs. $103 \mu \mathrm{m})$, and the highest value was 163 $\mu \mathrm{m}$ at $\mathrm{d} 84$.

Moreover, the jejunal crypt depth showed a quadratic increase $(P<0.01)$ over time (Table 5 and Supplemental Figure S4, https://doi.org/10.6084/m9.figshare .17111312.v1); it was higher at $\mathrm{d} 70$ than $\mathrm{d} 28$ and d 28 than d 14 (360, 290, and $230 \mu \mathrm{m}$, respectively). Moreover, the jejunal muscle layer thickness was higher $(P<0.01)$ at $\mathrm{d} 42$ than $\mathrm{d} 14(147 \mathrm{vs} .119 \mu \mathrm{m})$ and $\mathrm{d} 70$ than d 28 (160 vs. $131 \mu \mathrm{m})$. However, the jejunal villus height and epithelial thickness showed a nonsignificant increase over time.

Moreover, the duodenal crypt depth was higher $(P<$ $0.01)$ at $d 56$ than $d 7$ and $d 7$ than $d 1$ (306, 267, and $216 \mu \mathrm{m}$, respectively; Table 5 and Supplemental Figure S5, https://doi.org/10.6084/m9.figshare.17111312.v1). In addition, the duodenal muscle layer thickness was higher $(P<0.05)$ at $\mathrm{d} 7$ than $\mathrm{d} 1(130$ vs. $105 \mu \mathrm{m}), \mathrm{d}$ $28(155 \mu \mathrm{m})$ than $\mathrm{d} 7, \mathrm{~d} 70(178 \mu \mathrm{m})$ than $\mathrm{d} 28$, and $\mathrm{d}$ 84 than $d 42(190$ vs. $155 \mu \mathrm{m})$. The duodenal epithelial thickness was higher $(P<0.05)$ at $\mathrm{d} 42$ than $\mathrm{d} 28(27.7$ vs. $24.1 \mu \mathrm{m})$. However, the duodenal villus height did not show significant differences over time.

\section{DISCUSSION}

\section{Body Weight and Carcass Weight}

Age was the main factor influencing the BW and HCW from birth to $\mathrm{d} 70$, whereas the feeding system (supplemental feeding vs. grazing) had no significant effect (Jiao et al., 2015b). However, in this study, the MMSD phase showed the highest absolute growth of
BW and HCW and the highest dressing percentage. The improvement of body size indices was slow in the milk phase, whereas it was remarkable in the MMSD phase. In addition, the weaning transition is an essential phase for the manipulation of rumen development using nutritional strategies, which can affect ruminant growth performance and health (Sun et al., 2021). The current study results confirmed the beneficial effects of solid feed to enhance the preweaning growth and overcome the weaning stress. Providing solid diet, even in a small quantity during suckling, allows the development of rumen, which is necessary to counteract the stress caused by lack of nutrients, digestion inefficiency, and weight loss after weaning (Khan et al., 2011; Guzman et al., 2016). Alfalfa and starter before weaning improved rumen development and growth performance in lambs (Yang et al., 2015, 2018) and calves (Cui et al., 2020).

\section{Organ Development}

Organ development is important (e.g., the liver serves as the primary site of ketogenesis in the preruminant, and its ketogenic function decreases in the ruminating animal; Baldwin, 1999). This study showed a significant increase in organ weight over time, and the organ percentage to BW decreased. Similarly, the slaughter weight increased with the decline in noncarcass components and internal organ percentage in goats (Marichal et al., 2003; Peña et al., 2007; Kaić et al., 2012). In addition, solid feed stimulates rumen development to achieve better organ growth (e.g., liver and heart; Hamada et al., 1976).

\section{Anatomic Development of Stomach}

Our outcomes revealed that the rumen development in goats continued to increase significantly until d 70 . Similarly, Jiao et al. (2015b) found that the rumen anatomic development is achieved after 2 mo. The results showed an increased rumen growth rate in the OSD phase. At the same time, the OSD phase showed a subtle decline in the absolute growth of BW and a significant decrease in the absolute growth of $\mathrm{HCW}$ when compared with the MMSD phase. During the transition weaning phase, the animals experienced a slight decline in BW as a substitute to supply the development of the ruminal tissue and its microbial communities (Heinrichs, 2005). Similarly, lower BW and higher rumen weight were observed in newborn calves offered milk and starter than calves offered only milk (Guzman et al., 2016). Therefore, there is a priority for developing the rumen and its digestive function, which could af- 


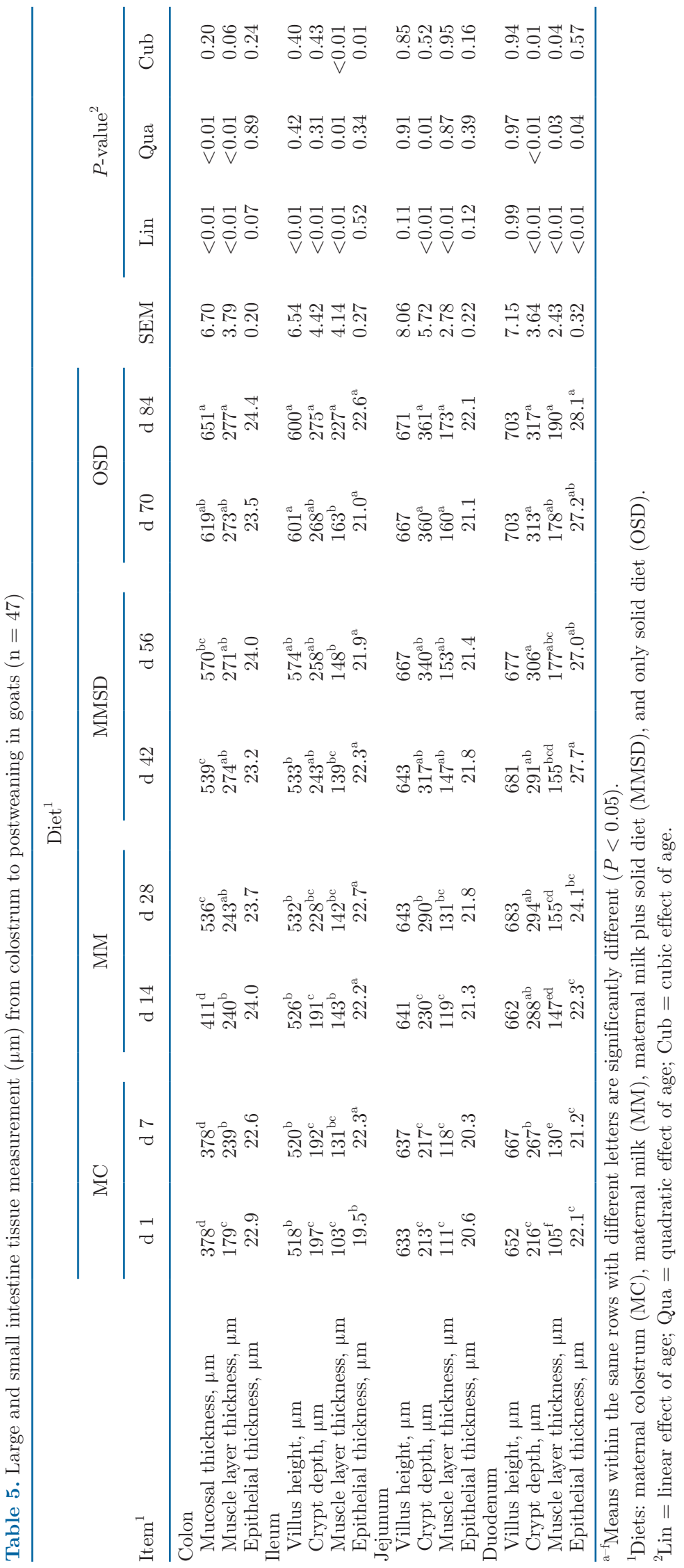


fect the substantial growth of small ruminants (Jelínek, 1995; Paez Lama et al., 2014).

Furthermore, the early solid feed promoted rumen development and its microbial contents and total VFA concentration (Sun et al., 2018; Lv et al., 2019; Wang et al., 2019). The newborn calves that received only MM or MR without solid feed had a limited capacity of ruminal fermentation, absorption of VFA, and metabolic activity in the rumen epithelium (Cozzi et al., 2002; Heinrichs, 2005). Similarly, Wang et al. (2016a) stated that the starter diet decreased milk intake, increased rumen fiber, and modulated the rumen bacteria. Accordingly, solid feed is associated with increased rumen weight and better health and growth (Baldwin et al., 2004; Sun et al., 2018). In addition, the starter diet increased the reticulorumen weight and volume as well as papillae height (Wang et al., 2016b). Furthermore, the starter diet increased total, epithelial, and muscle wet weights of the rumen and omasum as a percentage of the empty BW (Baldwin, 1999). In contrast, the reticulum and abomasum were not affected by dietary treatment (Baldwin, 1999). The abilities of solid feed as a stimulator for rumen development depend on its nutrient compositions, which can fulfill the rumen nutritional requirement for growth (Yáñez-Ruiz et al., 2015). In addition, age and BW are vital factors for rumen development (Frandson et al., 2009). Therefore, Zhuang et al. (2020) demonstrated that age, solid feeds, and weaning factors play a crucial role in shaping the gut microbiota and modulating rumen development.

\section{Rumen Histomorphology}

A well-developed rumen is essential for the absorption and metabolism of nutrients such as VFA to maintain rumen homeostasis and provide energy for the host, which has a long-term effect on later performance and health (Heinrichs and Heinrichs, 2011; Yáñez-Ruiz et al., 2015). The papillae height is an essential indicator for evaluating rumen anatomic development, followed by papillae width and the muscle layer thickness (Lesmeister et al., 2004). In the present study, the rumen papillae height and width increased significantly over time. Similar results were observed in goats with natural grazing and supplementary feeds (Jiao et al., 2015b) and calves fed concentrate with different carbohydrate sources (Suárez et al., 2006). The corneum thickness, the number of cells in the corneum, epithelium thickness, and the spinosum and basal layer thicknesses increased more in weaned calves than preweaning calves (van Niekerk et al., 2021). The structural rumen development positively relates to rumen fermentation products produced by microorganisms (Zou et al., 2020). The ruminal VFA concentration increased with increasing age from birth to d 70 (Jiao et al., 2015b), which could be related to the effect of age on gut microorganisms (Jiao et al., 2015a; Li et al., 2019a; Zhang et al., 2019). Therefore, age is the primary factor regulating rumen epithelial proliferation (Baldwin et al., 2004).

Newborn goats have a smooth rumen epithelium with no prominent rumen papillae. Declines in ruminal weight, rumen papillae, degree of keratinization, pigmentation, and muscular wall development have been observed in calves fed liquid feeds (Gilliland et al., 1962; Tamate et al., 1962). In preruminant animals, milk flows into the abomasum through the esophageal groove, resulting in less fermentation substrates for rumen development (Jiao et al., 2015a). The rumen growth in the absence of VFA is driven by the nutrient content of milk (Khan et al., 2016). Liquid feeds limit the metabolic activity in the rumen epithelium and the VFA absorption (Heinrichs, 2005), which slows down the development (Foley et al., 2009).

As the goats increased in age and the liquid diet changed to solid, the rumen development increased. The solid feed is the main diet for rumen epithelium development (Sun et al., 2021). The solid meal is the source of readily fermentable carbohydrates. It provides more carbon and nitrogen to produce microbial CP and VFA (Yang, 2002; Jiao et al., 2015b; Cui et al., 2020). In addition, the AA and fatty acid metabolism function in the rumen epithelia increases with the introduction of concentrate starters (Sun et al., 2021). The VFA provide an energy source for rumen development during early life (Baldwin, 1999; Jiao et al., 2015b; Lv et al., 2019). Diet energy is associated with rumen epithelium development and future growth performance (Shen et al., 2004). Moreover, solid feed enhances the expression of genes involved in VFA absorption and cell proliferation in the rumen (Metzler-Zebeli et al., 2013; Yan et al., 2014). The concentrate diet introduction to calves activates molecular pathways and biological processes in the morphological and functional development of the rumen wall (Connor et al., 2014). In addition, solid feeds decrease rumen $\mathrm{pH}$, increasing the blood flow to rumen tissues (Castillejos et al., 2006). Subsequently, the rumen volume, rumen tissue growth, and rumen papillary are higher in dry feed than milk (Suárez et al., 2006). In addition, starter feeding promotes rumen papillae height and width, epithelial thickness, and stratum corneum thickness of rumen epithelium tissue (Sun et al., 2018). Moreover, Cui et al. (2020) showed the increased rumen papillae height and width, and muscle layer thickness of rumen by starter intake. The rumen epithelial thickness and rumen papillary were improved in solid feed (Sun et al., 2021). 


\section{Intestine Histomorphology}

The morphology of intestinal villus and crypt is an important indicator for evaluating intestinal health and the absorptive capacity of nutrients ( $\mathrm{Li}$ et al., 2016). The intestinal tract is the central part of the liquid feed absorption and metabolism in preweaning ruminants (Zhang et al., 2021). However, few studies have been conducted about intestine development compared with rumen development (Hou et al., 2018). The short-chain fatty acid and lactic acid concentrations were higher in the colon than rumen during the first 4 wk of Holstein calves (Castro et al., 2016), indicating better fermentation activity. The colonic muscle layer thickness, duodenal muscle layer thickness and crypt depth, and the ileal epithelial thickness increased in the MC phase. Similarly, the colonic mucosal thickness, jejunal crypt depth, and duodenal muscle layer thickness increased in the colostrum and milk diets (Gerrits et al., 1998; Shen et al., 2004; Blum, 2006). However, a negative effect on intestinal development in calves was observed by delaying the first colostrum (Fischer-Tlustos et al., 2020) and MR feeding instead of colostrum (Blättler et al., 2001).

The roles of $\mathrm{MC}$ and $\mathrm{MM}$ intestinal development have been studied extensively in neonatal ruminants (Blum and Baumrucker, 2002), whereas the intestinal response to weaning, nutrition, and rumen development require further investigations. The rumen development that can be used to evaluate weaning programs has a close relationship with intestinal tract development (Górka et al., 2011). The rumen becomes the main digestion and absorption site instead of the intestine during the weaning transition (Dias et al., 2018), affecting the intestine development. The growth of the intestine is affected by different metabolic and atrophic hormones and chemical and physical dietary factors. Accordingly, the increased metabolic energy intake and dietary forge increased ruminal and intestinal growth through cellular hyperplasia in lambs (McLeod and Baldwin, 2000). Therefore, the morphology of small and large intestine sections improved in starter diet and VFA-infused groups (Baldwin, 1999). The highconcentrate diet improved the duodenal villus height and crypt depth and jejunal villus height (Zitnan et al., 2003). Moreover, the intestinal digestion-absorption function and the villus height and crypt depth of the duodenum, jejunum, and ileum were improved in calves fed alfalfa and starter diet (Cui et al., 2020). In the current study, the crypt depth of ileum and muscle layer thickness of jejunum increased in the MMSD phase. Moreover, the villus height of ileum and crypt depth of jejunum increased in the OSD phase.
It has been reported that the intestinal mass is not affected by the physical form of feed for either MR or pelleted lamb starter (Baldwin, 1999). The intestinal capacity for nutrient assimilation may increase over time (Baldwin, 1999). The cecum and colon varied over 3 time points $(1,42$, and $70 \mathrm{~d}$ ), indicating the role of age (Li et al., 2019b). The ileal villus height and crypt depth in newborn calves increased over time (Zhang et al., 2017). The small intestine morphology was affected by age and feeding system, especially the proximal portions (duodenum and jejunum) compared to the ileum (Li et al., 2016). For instance, Li et al. (2016) showed an increase of crypt depth in the jejunum and ileum with increasing age, which agrees with our study. In addition, the changes in intestine morphology parameters over time in this study showed the earlier stage of maturation of the intestine compared with rumen, which agrees with $\mathrm{Li}$ et al. (2016).

\section{CONCLUSIONS}

The absolute growth of carcass and the dressing percentage was lower at the post- than the preweaning stage, indicating weaning stress. The rumen weight and morphology improved from pre- to postweaning, and its development was achieved after 2 mo of age. The solid starter displayed a crucial role in promoting rumen development. Adequate nutrition and solid feed before weaning are recommended for the rapid development of the gastrointestinal tract and the improvement of growth performance of goats. The intestine morphological parameters increased over time, mainly at the earlier stages of milk feeding, indicating the critical role of the small intestine for milk digestion. In comparison, the morphological evolution of the intestine after weaning could be associated with rumen development and hence the nutrient availability. In addition, beyond feed composition, age was an important factor in increasing the structural development of rumen papillary to endure the shortage of MM and the consumption of solid feed to favor the digestive function and performance of the host.

\section{ACKNOWLEDGMENTS}

The study data are available on request from the corresponding author. This research was funded by the Inner Mongolia Science and Technology Key Project (2021SZD0014; Inner Mongolia, China), the Cooperative Guidance Project "Prospering Inner Mongolia through Science and Technology" in 2021 (2021CG0024; Inner Mongolia, China), and the National Natural Science Foundation of China (31872385; Beijing, China). 
The authors thank the staff of Xiang Feng black goat farm (Shandong, China) for assistance with animal handling and the collection of samples. The authors also thank the staff of Jianmin Wang Laboratory in the College of Animals Sciences and Veterinary Medicine of Shandong Agricultural University (Shandong, China). The authors have not stated any conflicts of interest.

\section{REFERENCES}

AOAC International. 2003. Official Methods of Analysis. 17th ed. AOAC International.

AOAC International. 2006. Official Methods of Analysis. 18th ed. AOAC International.

Baldwin, R. L. 1999. The proliferative actions of insulin, insulin-like growth factor-I, epidermal growth factor, butyrate and propionate on ruminal epithelial cells in vitro. Small Rumin. Res. 32:261-268. https://doi.org/10.1016/S0921-4488(98)00188-6.

Baldwin, R. L., K. R. McLeod, J. L. Klotz, and R. N. Heitmann. 2004. Rumen development, intestinal growth and hepatic metabolism in the pre- and postweaning ruminant. J. Dairy Sci. 87:E55-E65. https://doi.org/10.3168/jds.S0022-0302(04)70061-2.

Blättler, U., H. M. Hammon, C. Morel, C. Philipona, A. Rauprich, V. Romé, I. Le Huërou-Luron, P. Guilloteau, and J. W. Blum. 2001. Feeding colostrum, its composition and feeding duration variably modify proliferation and morphology of the intestine and digestive enzyme activities of neonatal calves. J. Nutr. 131:1256-1263. https://doi.org/10.1093/jn/131.4.1256.

Blum, J. W. 2006. Nutritional physiology of neonatal calves. J. Anim. Physiol. Anim. Nutr. (Berl.) 90:1-11. https://doi.org/10.1111/j .1439-0396.2005.00614.x.

Blum, J. W., and C. R. Baumrucker. 2002. Colostral and milk insulinlike growth factors and related substances: Mammary gland and neonatal (intestinal and systemic) targets. Domest. Anim. Endocrinol. 23:101-110. https://doi.org/10.1016/S0739-7240(02)00149 -2 .

Castillejos, L., S. Calsamiglia, and A. Ferret. 2006. Effect of essential oil active compounds on rumen microbial fermentation and nutrient flow in in vitro systems. J. Dairy Sci. 89:2649-2658. https:// doi.org/10.3168/jds.S0022-0302(06)72341-4.

Castro, J. J., A. Gomez, B. White, J. R. Loften, and J. K. Drackley. 2016. Changes in the intestinal bacterial community, short-chain fatty acid profile, and intestinal development of preweaned Holstein calves. 2. Effects of gastrointestinal site and age. J. Dairy Sci. 99:9703-9715. https://doi.org/10.3168/jds.2016-11007.

Chai, J., Q. Diao, J. Zhao, H. Wang, K. Deng, M. Qi, M. Nie, and N. Zhang. 2018. Effects of rearing system on meat quality, fatty acid and amino acid profiles of Hu lambs. Anim. Sci. J. 89:1178-1186. https://doi.org/10.1111/asj.13013.

Connor, E. E., R. L. Baldwin, M. P. Walker, S. E. Ellis, C. Li, S. Kahl, H. Chung, and R. W. Li. 2014. Transcriptional regulators transforming growth factor- $\beta 1$ and estrogen-related receptor- $\alpha$ identified as putative mediators of calf rumen epithelial tissue development and function during weaning. J. Dairy Sci. 97:4193-4207. https://doi.org/10.3168/jds.2013-7471.

Cozzi, G., F. Gottardo, S. Mattiello, E. Canali, E. Scanziani, M. Verga, and I. Andrighetto. 2002. The provision of solid feeds to veal calves: I. Growth performance, forestomach development, and carcass and meat quality. J. Anim. Sci. 80:357-366. https://doi.org/ $10.2527 / 2002.802357 x$

Cui, Z., S. Wu, J. Li, Q. E. Yang, S. Chai, L. Wang, X. Wang, X. Zhang, S. Liu, and J. Yao. 2020. Effect of alfalfa hay and starter feeding intervention on gastrointestinal microbial community, growth and immune performance of yak calves. Front. Microbiol. 11:994. https://doi.org/10.3389/fmicb.2020.00994.

Diao, Q., R. Zhang, and T. Fu. 2019. Review of strategies to promote rumen development in calves. Animals (Basel) 9:490. https://doi .org/10.3390/ani9080490.
Dias, J., M. I. Marcondes, S. Motta de Souza, B. Cardoso da Mata e Silva, M. Fontes Noronha, R. Tassinari Resende, F. S. Machado, H. Cuquetto Mantovani, K. A. Dill-McFarland, and G. Suen. 2018. Bacterial community dynamics across the gastrointestinal tracts of dairy calves during preweaning development. Appl. Environ. Microbiol. 84:e02675. https://doi.org/10.1128/AEM.02675-17.

Fischer-Tlustos, A. J., J. Pyo, Y. Song, D. L. Renaud, L. L. Guan, and M. A. Steele. 2020. Short communication: Effect of delaying the first colostrum feeding on small intestinal histomorphology and serum insulin-like growth factor-1 concentrations in neonatal male Holstein calves. J. Dairy Sci. 103:12109-12116. https://doi.org/10 $.3168 /$ jds.2020-18966.

Foley, P. A., D. A. Kenny, J. J. Callan, T. M. Boland, and F. P. O'Mara. 2009. Effect of DL-malic acid supplementation on feed intake, methane emission, and rumen fermentation in beef cattle. J. Anim. Sci. 87:1048-1057. https://doi.org/10.2527/jas.2008-1026.

Frandson, R., W. Wilke, and A. Fails. 2009. Anatomy and Physiology of Farm Animals. Wiley.

Gerrits, W. J., E. Decuypere, M. W. Verstegen, and V. Karabinas. 1998. Effect of protein and protein-free energy intake on plasma concentrations of insulin-like growth factor I and thyroid hormones in preruminant calves. J. Anim. Sci. 76:1356-1363. https://doi .org/10.2527/1998.7651356x.

Gilliland, R. L., L. Bush, and J. Friend. 1962. Relation of ration composition to rumen development in early-weaned dairy calves with observations on ruminal parakeratosis. J. Dairy Sci. 45:1211-1217. https://doi.org/10.3168/jds.S0022-0302(62)89598-8.

Górka, P., Z. Kowalski, P. Pietrzak, A. Kotunia, W. Jagusiak, and R. Zabielski. 2011. Is rumen development in newborn calves affected by different liquid feeds and small intestine development? J. Dairy Sci. 94:3002-3013. https://doi.org/10.3168/jds.2010-3499.

Guzman, C. E., L. T. Bereza-Malcolm, B. De Groef, and A. E. Franks. 2016. Uptake of milk with and without solid feed during the monogastric phase: Effect on fibrolytic and methanogenic microorganisms in the gastrointestinal tract of calves. Anim. Sci. J. 87:378388. https://doi.org/10.1111/asj.12429.

Hamada, T., S. Maeda, and K. Kameoka. 1976. Factors influencing growth of rumen, liver, and other organs in kids weaned from milk replacers to solid foods. J. Dairy Sci. 59:1110-1118. https://doi .org/10.3168/jds.S0022-0302(76)84330-5.

Heinrichs, A. J., and B. S. Heinrichs. 2011. A prospective study of calf factors affecting first-lactation and lifetime milk production and age of cows when removed from the herd. J. Dairy Sci. 94:336-341. https://doi.org/10.3168/jds.2010-3170.

Heinrichs, J. 2005. Rumen development in the dairy calf. Adv. Dairy Technol. 17:179-187.

Hou, L., Z. Ji, G. Wang, J. Wang, T. Chao, and J. Wang. 2018. Identification and characterization of microRNAs in the intestinal tissues of sheep (Ovis aries). PLoS One 13:e0193371. https://doi .org/10.1371/journal.pone.0193371.

Jelínek, K. 1995. Development of the forestomach of the goat (Capra aegagrus f. hircus) in the postnatal period. Acta Vet. Brno 64:4961. https://doi.org/10.2754/avb199564010049.

Jiao, J., J. Huang, C. Zhou, and Z. Tan. 2015a. Taxonomic identification of ruminal epithelial bacterial diversity during rumen development in goats. Appl. Environ. Microbiol. 81:3502-3509. https:// doi.org/10.1128/AEM.00203-15.

Jiao, J., X. Li, K. A. Beauchemin, Z. Tan, S. Tang, and C. Zhou. 2015b. Rumen development process in goats as affected by supplemental feeding v. grazing: age-related anatomic development, functional achievement and microbial colonisation. Br. J. Nutr. 113:888-900. https://doi.org/10.1017/S0007114514004413.

Jiao, J., J. Wu, C. Zhou, S. Tang, M. Wang, and Z. Tan. 2016. Composition of ileal bacterial community in grazing goats varies across non-rumination, transition and rumination stages of life. Front. Microbiol. 7:1364. https://doi.org/10.3389/fmicb.2016.01364.

Jin, Y. M., C. Jiang, X. Q. Zhang, L. F. Shi, and M. Z. Wang. 2018. Effect of dietary Urtica cannabina on the growth performance, apparent digestibility, rumen fermentation and gastrointestinal morphology of growing lambs. Anim. Feed Sci. Technol. 243:1-9. https://doi.org/10.1016/j.anifeedsci.2018.06.014. 
Kaić, A., A. Cividini, and K. Potočnik. 2012. Influence of sex and age at slaughter on growth performance and carcass traits of Boer kids. Acta Agric. Slov. 100:281-285.

Khan, M. A., A. Bach, D. M. Weary, and M. A. G. von Keyserlingk. 2016. Invited review: Transitioning from milk to solid feed in dairy heifers. J. Dairy Sci. 99:885-902. https://doi.org/10.3168/jds.2015 $-9975$.

Khan, M. A., D. M. Weary, and M. A. von Keyserlingk. 2011. Invited review: Effects of milk ration on solid feed intake, weaning, and performance in dairy heifers. J. Dairy Sci. 94:1071-1081. https:// doi.org/10.3168/jds.2010-3733.

Lesmeister, K. E., P. R. Tozer, and A. J. Heinrichs. 2004. Development and analysis of a rumen tissue sampling procedure. J. Dairy Sci. 87:1336-1344. https://doi.org/10.3168/jds.S0022-0302(04)73283 $-\mathrm{X}$.

Li, B., K. Zhang, C. Li, X. Wang, Y. Chen, and Y. Yang. 2019a. Characterization and comparison of microbiota in the gastrointestinal tracts of the goat (Capra hircus) during preweaning development. Front. Microbiol. 10:2125. https://doi.org/10.3389/fmicb.2019 .02125 .

Li, H. Z., T. Ran, Z. X. He, Q. X. Yan, S. X. Tang, and Z. L. Tan. 2016. Postnatal developmental changes of the small intestinal villus height, crypt depth and hexose transporter mRNA expression in supplemental feeding and grazing goats. Small Rumin. Res. 141:106-112. https://doi.org/10.1016/j.smallrumres.2016.07.012.

Li, Z., H. Si, W. Nan, X. Wang, T. Zhang, and G. Li. 2019b. Bacterial community and metabolome shifts in the cecum and colon of captive sika deer (Cervus nippon) from birth to post weaning. FEMS Microbiol. Lett. 366:fnz010. https://doi.org/10.1093/ femsle/fnz010

Liu, J., G. Bian, D. Sun, W. Zhu, and S. Mao. 2017. Starter feeding supplementation alters colonic mucosal bacterial communities and modulates mucosal immune homeostasis in newborn lambs. Front. Microbiol. 8:429. https://doi.org/10.3389/fmicb.2017.00429.

Liu, S. S., X. B. Wang, Y. F. Shen, Y. X. Sun, D. S. Luan, Z. Y. Yang, J. Y. Chang, S. D. Wei, H. F. Cao, and Y. H. Xu. 2012. Conservation and utilization and developmental measures of Laiwu Black Goat. J. Domest. Anim. Ecol. 33:102-105.

Lopez-Pedrosa, J. M., M. I. Torres, M. I. Fernández, A. Ríos, and A. Gil. 1998. Severe Malnutrition alters lipid composition and fatty acid profile of small intestine in newborn piglets. J. Nutr. 128:224233. https://doi.org/10.1093/jn/128.2.224.

Lv, X., J. Chai, Q. Diao, W. Huang, Y. Zhuang, and N. Zhang. 2019. The signature microbiota drive rumen function shifts in goat kids introduced to solid diet regimes. Microorganisms 7:516. https:// doi.org/10.3390/microorganisms7110516.

Paez Lama, S., D. Grilli, V. Egea, M. Fucili, L. Allegretti, and J. C. Guevara. 2014. Rumen development and blood metabolites of Criollo kids under two different rearing systems. Livest. Sci. 167:171-177. https://doi.org/10.1016/j.livsci.2014.06.018.

Marichal, A., N. Castro, J. Capote, N. Zamorano, and A. Arguello. 2003. Effects of live weight at slaughter $(6,10$ and $25 \mathrm{~kg}$ ) on kid carcass and meat quality. Livest. Prod. Sci. 83:247-256. https:// doi.org/10.1016/S0301-6226(03)00113-1.

McLeod, K. R., and R. L. Baldwin. 2000. Effects of diet forage: concentrate ratio and metabolizable energy intake on visceral organ growth and in vitro oxidative capacity of gut tissues in sheep. J. Anim. Sci. 78:760-770. https://doi.org/10.2527/2000.783760x.

Merchant, H. A., F. Liu, M. Orlu Gul, and A. W. Basit. 2016. Agemediated changes in the gastrointestinal tract. Int. J. Pharm. 512:382-395. https://doi.org/10.1016/j.ijpharm.2016.04.024.

Metzler-Zebeli, B. U., M. Hollmann, S. Sabitzer, L. Podstatzky-Lichtenstein, D. Klein, and Q. Zebeli. 2013. Epithelial response to highgrain diets involves alteration in nutrient transporters and $\mathrm{Na}+/$ $\mathrm{K}+$-ATPase mRNA expression in rumen and colon of goats. J. Anim. Sci. 91:4256-4266. https://doi.org/10.2527/jas.2012-5570.

National Bureau of Statistics of China. 2020. China Statistical Yearbook 2020. China Statistics Press.

NRC. 2001. Nutrient Requirements of Dairy Cattle. Vol. 7th revised ed. National Academy Press.
NRC. 2007. Nutrient requirements of small ruminants: Sheep, goats, cervids, and new world camelids. National Academy Press.

Peña, F., J. Perea, A. Garcia, and R. Acero. 2007. Effects of weight at slaughter and sex on the carcass characteristics of Florida suckling kids. Meat Sci. 75:543-550. https://doi.org/10.1016/j.meatsci 2006.09.004.

Saro, C., U. M. Hohenester, M. Bernard, M. Lagree, C. Martin, M. Doreau, H. Boudra, M. Popova, and D. P. Morgavi. 2018. Effectiveness of interventions to modulate the rumen microbiota composition and function in pre-ruminant and ruminant lambs. Front. Microbiol. 9:1273. https://doi.org/10.3389/fmicb.2018.01273.

Shen, Z., H. M. Seyfert, B. Lohrke, F. Schneider, R. Zitnan, A. Chudy, S. Kuhla, H. M. Hammon, J. W. Blum, H. Martens, H. Hagemeister, and J. Voigt. 2004. An energy-rich diet causes rumen papillae proliferation associated with more IGF type 1 receptors and increased plasma IGF-1 concentrations in young goats. J. Nutr. 134:11-17. https://doi.org/10.1093/jn/134.1.11.

Suárez, B. J., C. G. Van Reenen, G. Beldman, J. van Delen, J. Dijkstra, and W. J. Gerrits. 2006. Effects of supplementing concentrates differing in carbohydrate composition in veal calf diets: I. Animal performance and rumen fermentation characteristics. J. Dairy Sci. 89:4365-4375. https://doi.org/10.3168/jds.S0022-0302(06)72483 -3 .

Sun, D., Y. Yin, C. Guo, L. Liu, S. Mao, W. Zhu, and J. Liu. 2021. Transcriptomic analysis reveals the molecular mechanisms of rumen wall morphological and functional development induced by different solid diet introduction in a lamb model. J. Anim. Sci. Biotechnol. 12:33. https://doi.org/10.1186/s40104-021-00556-4.

Sun, D. M., S. Y. Mao, W. Y. Zhu, and J. H. Liu. 2018. Effect of starter diet supplementation on rumen epithelial morphology and expression of genes involved in cell proliferation and metabolism in pre-weaned lambs. Animal 12:2274-2283. https://doi.org/10.1017/ S1751731118000290.

Tamate, H., A. McGilliard, N. Jacobson, and R. Getty. 1962. Effect of various dietaries on the anatomical development of the stomach in the calf. J. Dairy Sci. 45:408-420. https://doi.org/10.3168/jds .S0022-0302(62)89406-5.

van Niekerk, J. K., M. Middeldorp, L. Guan, and M. Steele. 2021. Preweaning to postweaning rumen papillae structural growth, ruminal fermentation characteristics, and acute-phase proteins in calves. J. Dairy Sci. 104:3632-3645. https://doi.org/10.3168/jds.2020-19003.

Van Soest, P. J., J. B. Robertson, and B. A. Lewis. 1991. Methods for dietary fiber, neutral detergent fiber, and nonstarch polysaccharides in relation to animal nutrition. J. Dairy Sci. 74:3583-3597. https://doi.org/10.3168/jds.S0022-0302(91)78551-2.

Wang, K., X. Liu, T. Qi, Y. Hui, H. Yan, L. Qu, X. Lan, and C. Pan. 2021. Whole-genome sequencing to identify candidate genes for litter size and to uncover the variant function in goats (Capra hircus). Genomics 113:142-150. https://doi.org/10.1016/j.ygeno 2020.11.024.

Wang, L., Q. Xu, F. Kong, Y. Yang, D. Wu, S. Mishra, and Y. Li. 2016a. Exploring the goat rumen microbiome from seven days to two years. PLoS One 11:e0154354. https://doi.org/10.1371/ journal.pone.0154354.

Wang, S., T. Ma, G. Zhao, N. Zhang, Y. Tu, F. Li, K. Cui, Y. Bi, H. Ding, and Q. Diao. 2019. Effect of age and weaning on growth performance, rumen fermentation, and serum parameters in lambs fed starter with limited ewe-lamb interaction. Animals (Basel) 9:825 https://doi.org/10.3390/ani9100825.

Wang, W., C. Li, F. Li, X. Wang, X. Zhang, T. Liu, F. Nian, X. Yue, F. Li, X. Pan, Y. La, F. Mo, F. Wang, and B. Li. 2016b. Effects of early feeding on the host rumen transcriptome and bacterial diversity in lambs. Sci. Rep. 6:32479. https://doi.org/10.1038/ srep32479

Yan, L., B. Zhang, and Z. Shen. 2014. Dietary modulation of the expression of genes involved in short-chain fatty acid absorption in the rumen epithelium is related to short-chain fatty acid concentration and $\mathrm{pH}$ in the rumen of goats. J. Dairy Sci. 97:5668-5675. https://doi.org/10.3168/jds.2013-7807.

Yáñez-Ruiz, D. R., L. Abecia, and C. J. Newbold. 2015. Manipulating rumen microbiome and fermentation through interventions during 
early life: A review. Front. Microbiol. 6:1133. https://doi.org/10 .3389/fmicb.2015.01133.

Yang, B., B. He, S. S. Wang, J. X. Liu, and J. K. Wang. 2015. Early supplementation of starter pellets with alfalfa improves the performance of pre- and postweaning Hu lambs. J. Anim. Sci. 93:49844994. https://doi.org/10.2527/jas.2015-9266.

Yang, B., J. Le, P. Wu, J. Liu, L. L. Guan, and J. Wang. 2018. Alfalfa intervention alters rumen microbial community development in hu lambs during early life. Front. Microbiol. 9:574. https://doi.org/10 .3389/fmicb.2018.00574.

Yang, C. M. 2002. Response of forage fiber degradation by ruminal microorganisms to branched-chain volatile fatty acids, amino acids, and dipeptides. J. Dairy Sci. 85:1183-1190. https://doi.org/10 .3168/jds.S0022-0302(02)74181-7.

Zhang, K., B. Li, M. Guo, G. Liu, Y. Yang, X. Wang, Y. Chen, and E. Zhang. 2019. Maturation of the goat rumen microbiota involves three stages of microbial Colonization. Animals (Basel) 9:1028 https://doi.org/10.3390/ani9121028.

Zhang, X., X. Wu, W. Chen, Y. Zhang, Y. Jiang, Q. Meng, and Z. Zhou. 2017. Growth performance and development of internal organ, and gastrointestinal tract of calf supplementation with calcium propionate at various stages of growth period. PLoS One 12:e0179940. https://doi.org/10.1371/journal.pone.0179940.
Zhang, Y., S. H. Choi, K. M. Nogoy, and S. Liang. 2021. Review: The development of the gastrointestinal tract microbiota and intervention in neonatal ruminants. Animal 15:100316. https://doi.org/10 .1016/j.animal.2021.100316.

Zhuang, Y., J. Chai, K. Cui, Y. Bi, Q. Diao, W. Huang, H. Usdrowski, and N. Zhang. 2020. Longitudinal investigation of the gut microbiota in goat kids from birth to postweaning. Microorganisms 8:1111. https://doi.org/10.3390/microorganisms8081111.

Zitnan, R., S. Kuhla, K. Nurnberg, U. Schonhusen, Z. Ceresnakova, A. Sommer, M. Baran, G. Greserova, and J. Voigt. 2003. Influence of the diet on the morphology of ruminal and intestinal mucosa and on intestinal carbohydrase levels in cattle. Vet. Med. (Praha) 48:177-182. https://doi.org/10.17221/5767-VETMED.

Zou, X., G. Liu, F. Meng, L. Hong, Y. Li, Z. Lian, Z. Yang, C. Luo, and D. Liu. 2020. Exploring the rumen and cecum microbial community from fetus to adulthood in goat. Animals (Basel) 10:1639. https://doi.org/10.3390/ani10091639.

\section{ORCIDS}

M. M. Abdelsattar @ https://orcid.org/0000-0002-1650-3062

N. Zhang @ (t) htps://orcid.org/0000-0001-6272-7553 